\title{
, \\ TD-Based Adaptive Output Feedback Control of Ship Heading with Stochastic Noise and Unknown Actuator Dead-Zone Input
}

\author{
Yanli Liu*(D, Runzhi Wang, Yuechao Zhao and Dongdong Mu
}

check for

updates

Citation: Liu, Y. ; Wang, R.; Zhao, Y.; $\mathrm{Mu}, \mathrm{D}$. TD-Based Adaptive Output Feedback Control of Ship Heading with Stochastic Noise and Unknown Actuator Dead-Zone Input. Appl. Sci. 2022, 12, 1985. https://doi.org/ 10.3390/app12041985

Academic Editors: Chang Yong Song and Wu Deng

Received: 30 December 2021 Accepted: 10 February 2022 Published: 14 February 2022

Publisher's Note: MDPI stays neutral with regard to jurisdictional claims in published maps and institutional affiliations.

Copyright: (C) 2022 by the authors. Licensee MDPI, Basel, Switzerland. This article is an open access article distributed under the terms and conditions of the Creative Commons Attribution (CC BY) license (https:// creativecommons.org/licenses/by/ $4.0 /)$.

\author{
The School of Marine Electrical Engineering, Dalian Maritime University, Dalian 116026, China; \\ wangrz1220@163.com (R.W.); zhaoyuechaoll@163.com (Y.Z.); ddmu@dlmu.edu.cn (D.M.) \\ * Correspondence: liuyanli@dlmu.edu.cn
}

\begin{abstract}
To meet the demand of ship control, a new heading control tactic is explored using switching theory. Different from the previous results, the stochastic noise and switched control are considered in the Norrbin nonlinear mathematical model concurrently to discuss ship heading control. Then, for the resulting systems, the adaptive control issue is addressed, while the dead-zone input is embedded and unknown. By establishing switched state observers for the corresponding subsystems, the conservatism of the common state observer can be reduced greatly, and the analysis can be achieved under the switching signal satisfying the average dwell time (ADT). The "explosion of terms" problem occurring in the backstepping technique is well remedied via an innovative tracking differentiator (TD) technology, which is an innovation in itself. According to the theory proof, under the developed control tactic, the resulting signals are then to be bounded in probability, with the tracking goal being achieved well. The theoretical design result was analyzed, and the corresponding validity is given through simulation experiments.
\end{abstract}

Keywords: ship heading tracking control; stochastic noise; dead-zone; tracking differentiator (TD); average dwell time (ADT)

\section{Introduction}

Currently, the shipping industry is vigorously developing, and ship transport has become one of the most effective and economical transportation methods to fulfill the trading of bulk goods between regions and countries, so the study of ship control has vital value [1-4]. Ship control is an important subject, as well as the application of control theory in the area of navigation technology research. Along with the evolution of control theory, various kinds of advanced control technologies and control theories have been applied to the design of ship controllers and have achieved ideal control effects [5-11]. Backstepping-based adaptive control technology emerged in the 1990s as a useful tool for analyzing and designing the controller of nonlinear systems. It has a relatively complete adaptive control theory and a nonlinear robust control theory for systems with uncertain parameters, and this method has been widely used in various works on ship operation control. It is important to note that this technique has the precondition that the controlled system functions are available or can be expressed as the product of uncertain constants and known functions. However, the marine environment is complex and changeable, and the ship mathematical model is also uncertain. At this time, when the ship control model cannot meet these restrictions, the above control design method will no longer be applicable. Therefore, many experts in the control field began to explore new technologies to solve this problems. Intelligent control technology (neural network or fuzzy logic system (FLS)) brings new research ideas to solve this kind of problem. The development of adaptive intelligent control technology not only promotes the development of the nonlinear control field, but also brings new hope for dealing with complex problems in ship control systems [12-16]. For example, using intelligent control technology, the 
adaptive output feedback control problem of an intelligent ship autopilot systems was addressed in [12]. It can be easily found that, in the backstepping design, the drawback of the "explosion of terms" is inescapable, and this greatly increases the difficulty and complexity of the calculations; thus, the resulting control tactics are sometimes not easy to apply in engineering. In addition to the usual methods, such as dynamic surface control (DSC) $[17,18]$, it can be seen that the above problem was similarly managed by the tracking differentiator (TD) technique in $[19,20]$, and the expected control target was successfully achieved. The TD technique has been proven to be a good tool, but few results on stochastic systems, even on ship control, have been reported. This is an interesting and meaningful work, which aroused our research interest.

In practice, the structure of a ship control system is intricate and changeable, with highly nonlinear characteristics and model uncertainty. In the control process, the ship control system is also susceptible to various external and stochastic noises, such as weather change, water velocity, and draft depth in complex sea conditions. It is necessary to consider the stochastic noise in the ship control performance when establishing the system mathematical model, as the requirements of actual engineering technology on system accuracy become higher and higher. The control of stochastic systems has become a vibrant research area recently, and numerous theoretical and applied works have been published [21-24]. Despite all these research achievements, however, there are few research results on the problem of ship control systems with stochastic noise at present [25-27], and these results ignore the switching mechanism in the analysis and control design. The switching control problem under different wind levels and water velocities needs to be considered. The core of the research of the switched system is to fuse discrete events and continuous time to analyze and control the actual engineering problem, and many valuable methods have been published simultaneously [28-32]. Compared with the deterministic ship control system, the research on the ship control system, which can be cast into switched stochastic nonlinear systems, has certain complexities and challenges, and such research is of practical significance for ship control.

In addition, the dead-zone characteristics of the marine steering gear actuator will affect the control precision. In order to reduce the influence of the dead-zone characteristics on the control system, many methods have been put forward by many scholars [33-36]. In order to ensure the safe navigation of the controlled ship heading systems, the dead-zone should not be ignored in the control design, which is of vital value. It is a very challenging problem to combine the auxiliary dead-zone compensation with the switching events and apply it to the ship heading tracking control design with stochastic disturbance, which is an important open issue to investigate in the ship control area.

This work intends to propose a useful adaptive control tactic for ship heading under unknown actuator dead-zone input described by the switched stochastic nonlinear model. Surpassing the existing results, the main novelties are as follows:

- When the environment disturbances are considered as stochastic components rather than just deterministic disturbances, the induction of the Hessian terms in the analysis of the Lyapunov function and the control design of the ship heading will introduce more difficulties than the results in [12];

- A novel control tactic was developed for the ship heading, which can be used to study the problem of the ship heading with or without stochastic noise. Compared with the results in $[19,20]$, the switching and stochastic disturbance were taken into account, which is more in line with the actual problem and makes the design more challenging. Such research has more practical significance and value than that of deterministic disturbances on the safe navigation of a ship, since there are too many stochastic factors during the voyage;

- The adaptive TD control tactics combined with the compensation signal smooths the "explosion of terms" occurring in the work [17,35]. Furthermore, the tracking goal of the considered ship heading was achieved with an improved control performance, which ensures safe and stable sailing. 


\section{Mathematical Preliminaries}

\subsection{System Model}

The mathematical model of the ship system is described as:

$$
T \dot{h}+h+\tau h^{3}=K \delta
$$

which is the Norrbin nonlinear mathematical model [3,12], where $T$ and $K$ denote the time constant and rudder gain, $h=\dot{\psi}$ is the yaw rate with $\psi$ the heading angle, $\tau$ denotes the Norrbin coefficient, and $\delta$ represents the rudder angle.

Considering that wind, waves, and ocean currents have a certain randomness in ship sailing, the stochastic noise was not taken into account in the above model (1), which lacks practical application. Furthermore, the dynamic equation of the nonlinear ship heading control system could be switched control at different levels of speed. In order to study the practical problems better, the aforementioned disturbance is denoted by a stochastic process $g_{\sigma(t)}^{T}(\psi, h)$, which is unknown. Then, System (1) is rewritten into the switched stochastic form:

$$
T_{\sigma(t)} \dot{h}+h+\tau_{\sigma(t)} h^{3}=K_{\sigma(t)} \delta_{\sigma(t)}+g_{\sigma(t)}^{T}(\psi, h) \omega
$$

where $\omega$ denotes the standard Brownian motion and $\sigma(t):[0, \infty) \rightarrow \mathfrak{L}=\{1, \cdots, l\}$ describes the switching law.

Let $x_{1}=\psi, x_{2}=h$, and $u_{\sigma(t)}=\frac{K_{\sigma(t)}}{T_{\sigma(t)}} \delta_{\sigma(t)}$, then we have the controlled switched stochastic Norrbin nonlinear model:

$$
\begin{aligned}
d x_{1} & =x_{2} d t, \\
d x_{2} & =\left(u_{\sigma(t)}+f_{\sigma(t)}\left(x_{2}\right)\right) d t+\frac{1}{T_{\sigma(t)}} g_{\sigma(t)}^{T}\left(x_{1}, x_{2}\right) d \omega, \\
y & =x_{1}
\end{aligned}
$$

where $f_{\sigma(t)}=-\frac{1}{T_{\sigma(t)}} x_{2}-\frac{\tau_{\sigma(t)}}{T_{\sigma(t)}} x_{2}^{3}$ is an unknown smoothing function.

Remark 1. Note that the Norrbin model is often utilized to analyze the performance and related control design of unmanned surface vehicles [3,12]. By contrast, the stochastic noise and switching theory have not been taken into account, and this will have certain limitations on the research of actual ship control problems. In actual navigation, uncertain stochastic influences and stochastic motion will occur in the ship control system due to the influence of wind and waves. To exhibit the influence of stochastic noise on heading tracking performance, the comparison test results are shown in the following. Considering the complexity and variability of the internal mechanisms on the switched stochastic nonlinear systems, the research of this work is more challenging and has more practical significance.

Here, $u_{k}=\Gamma_{k}\left(v_{k}\right)$ is the nonsymmetric and switched dead-zone nonlinearity in the controlled system [35]:

$$
u_{k}=\Gamma_{k}\left(v_{k}\right)= \begin{cases}m_{r, k}\left(v_{k}-b_{r, k}\right), & v_{k} \geq b_{r, k} \\ 0, & -b_{l, k}<v_{k}<b_{r, k} \\ m_{l, k}\left(v_{k}+b_{l, k}\right), & v_{k} \leq-b_{l, k}\end{cases}
$$

in which $m_{r, k}, m_{l, k}$ and $b_{r, k}, b_{l, k}$ are the nonsymmetric parameters of the dead-zone and are positive and unknown. Similar to the idea in [35], the following expression is formulated to carry out the tracking control smoothly:

$$
u_{k}=\Gamma_{k}^{\prime}\left(v_{k}\right)+\omega_{k}
$$


in which $\omega_{k}=\Gamma_{k}\left(v_{k}\right)-\Gamma_{k}^{\prime}\left(v_{k}\right)$ is the error and $\Gamma_{k}^{\prime}\left(v_{k}\right)$ is an unknown smoothing function, and there exists a constant $\bar{\omega}_{k}$ satisfying $\left|\omega_{k}\right| \leq \bar{\omega}_{k}$. In order to facilitate the problem, an unknown function $\sigma^{\prime}\left(v_{k}\right)=\Gamma_{k}^{\prime}\left(v_{k}\right)-v_{k}$ is defined, then one obtains:

$$
\begin{aligned}
u_{k} & =\Gamma_{k}^{\prime}\left(v_{k}\right)-v_{k}+v_{k}+\omega_{k} \\
& =v_{k}+\sigma^{\prime}\left(v_{k}\right)+\omega_{k} .
\end{aligned}
$$

For the actual controller, we let:

$$
v_{k}=v_{c k}-v_{\phi k}
$$

therefore, it yields:

$$
u_{k}=v_{c k}+\sigma_{k}^{\prime}\left(v_{k}\right)-v_{\phi k}+\omega_{k}
$$

It should be noted that $v_{\phi k}$ and $v_{c k}$ denote the introduced dead-zone input's compensator and the corresponding control law.

Remark 2. The dead-zone phenomenon is common and inevitable when the ship is in long-term working conditions, and many results on ship control with the dead-zone phenomenon have been reported $[33,34]$. Compared with them, the switching theory is considered in our work, and accordingly, the switched dead-zone nonlinearities are given for different subsystems, which is less conservative and more in line with the actual situation. The results developed in this work will have a positive effect on the actual ship control and ensure safe and stable navigation.

\subsection{Control Objective}

The adaptive output feedback tracking controllers are constructed for ship heading systems (3) with stochastic noise and dead-zone input (4) such that a desired signal $y_{d}(t)$ can be followed by the output under the ADT $\tau_{a}$, while the boundedness in the probability of the resulting systems is guaranteed.

Assumption 1. The continuous desirable heading signal $y_{d}(t)$ is bounded, and likewise for $\dot{y}_{d}(t)$.

Remark 3. The related adaptive backstepping control results require the knowledge of $y_{d}^{i}(t)$ $(i=0,1, \cdots, j-1)$, where $j$ is the order of the controlled system. Assumption 1 only needs $y_{d}(t)$ and $\dot{y}_{d}(t)$, which is less stringent, and the resulting heading control scheme is more suitable for actual ship control.

Lemma 1. Reference [22]: Consider the unknown function $f(\cdot) \in \Omega$. FLS $W^{T} S(\cdot)$ is utilized such that $W^{T} S(\cdot)+\delta(\cdot),|\delta(\cdot)| \leq \varepsilon$ with $\varepsilon>0$ an approximate error; $W=\left(w_{1}, \cdots, w_{P}\right)^{T}$ and $S(\cdot)=\frac{\left(s_{1}(\cdot), \cdots, s_{P}(\cdot)\right)^{T}}{\sum_{i=1}^{P} s_{i}(\cdot)}$ denote the ideal constant weight vector and the basis function vector; $P>1$ is the fuzzy rules' number, and $s_{i}(\cdot)=\exp \left(\frac{-\left(\cdot-\mu_{i}\right)^{T}\left(\cdot-\mu_{i}\right)}{\eta_{i}^{2}}\right)$; in the Gaussian function, $\mu_{i}$ and $\eta_{i}$ are the center vector and width, respectively; $i=1, \cdots, P$.

Lemma 2. Reference [22]: For a stochastic system with the hypothesis that there exist constants $p_{1}, p_{2}, \mathcal{K}_{\infty}$ functions $\bar{o}, \underline{o}$, a function $V \in C^{2}: R^{n} \rightarrow R^{+}$, for $\forall x \in R^{n}, t \geq 0$, such that if

$$
\left\{\begin{array}{l}
\bar{o}(|x|) \leq V(x) \leq \underline{o}(|x|) \\
\mathcal{L} V(x) \leq p_{1}-p_{2} V(x)
\end{array}\right.
$$

hold, then the boundedness in the probability holds. 
Definition 1. Reference [32]: For $N_{0} \geq 0, \tau_{a}>0$ and the switchings' number occurring in $\left[T_{1}, T_{2}\right)\left(N_{\sigma}\left(T_{2}, T_{1}\right)\right)$ satisfying:

$$
N_{\sigma}\left(T_{2}, T_{1}\right) \leq N_{0}+\frac{T_{2}-T_{1}}{\tau_{a}},
$$

then the switching signal $\sigma(t)$ of the considered switched system has an ADT $\tau_{a}$.

\section{Main Results}

\subsection{Adaptive Output Feedback Control Design}

A newly adaptive fuzzy controller based on a switched observer was designed by incorporating the TD method into the backstepping technique. Firstly, we construct the following switched state observers:

$$
\begin{aligned}
& d \hat{x}_{1}=\left(\hat{x}_{2}-l_{k, 1}\left(\hat{x}_{1}-y\right)\right) d t, \\
& d \hat{x}_{2}=\left(u_{k}-l_{k, 2}\left(\hat{x}_{1}-y\right)\right) d t,
\end{aligned}
$$

where $\hat{x}_{i}$ are the estimates of $x_{i}$, and constants $l_{k, i}>0(i=1,2)$ are chosen to make:

$$
A_{k}=\left[\begin{array}{ll}
-l_{k, 1} & 1 \\
-l_{k, 2} & 0
\end{array}\right]
$$

strictly Hurwitz; hence, for $\forall Q_{k}^{T}=Q_{k}>0$, positive definite matrices $P_{k}, A_{k}^{T} P_{k}+P_{k} A_{k}=$ $-Q_{k}$ hold.

Consider $\tilde{x}_{i}=x_{i}-\hat{x}_{i}$ as the errors, which satisfy $(i=1,2)$ :

$$
d \tilde{x}=\left(A_{k} \tilde{x}+F_{k}\right) d t+G_{k} d \omega,
$$

where $F_{k}=\left[0, f_{k}\right]^{T}, G_{k}=\left[0, \frac{1}{T} g_{k}^{T}\right]^{T}$ with $\left\|G_{k}^{T} G_{k}\right\| \leq \bar{\sigma}$, and $\bar{\sigma}$ is the bounded constant.

The following tracking error variables are determined before the control design:

$$
\begin{gathered}
z_{1}=x_{1}-y_{d}, \\
z_{2}=\hat{x}_{2}-\alpha_{2 d}, \\
\xi_{i}=z_{i}-\vartheta_{i}, \quad i=1,2,
\end{gathered}
$$

where $\xi_{i}$ is the new tracking error signal, and $\vartheta_{i}$ and $\alpha_{2 d}$ will be shown in detail in the control design.

Step 0. Consider the stochastic Lyapunov function below:

$$
V_{k 0}=\frac{r}{2}\left(\tilde{x}^{T} P_{k} \tilde{x}\right)^{2}
$$

where $r>0$ is a constant.

By combining (12) and (16), we obtain:

$$
\begin{aligned}
\mathcal{L} V_{k 0}= & -r\left(\tilde{x}^{T} P_{k} \tilde{x}\right) \tilde{x}^{T} Q_{k} \tilde{x}+2 r\left(\tilde{x}^{T} P_{k} \tilde{x}\right) \tilde{x}^{T} P_{k} F_{k} \\
& +r \operatorname{rr}\left\{G_{k}\left(2 P_{k} \tilde{x} \tilde{x}^{T} P_{k}+\tilde{x}^{T} P_{k} \tilde{x} P_{k}\right) G_{k}^{T}\right\} .
\end{aligned}
$$

Here, FLS $W_{0}^{T} S_{0}$ is introduced to approximate $F_{k}$, then:

$$
F_{k}=W_{0}^{T} S_{0}+\delta_{0},\left\|\delta_{0}\right\| \leq \varepsilon_{0},
$$

where $\varepsilon_{0}>0$ 
Under Young's inequality, it yields:

$$
\begin{aligned}
2 r\left(\tilde{x}^{T} P_{k} \tilde{x}\right) \tilde{x}^{T} P_{k} F_{k} & \leq \frac{3 r}{2} v_{0}^{\frac{4}{3}}\left\|P_{k}\right\|^{\frac{8}{3}}\|\tilde{x}\|^{4}+\frac{r}{2 v_{0}^{4}}\left(\theta^{2}+\varepsilon_{0}^{4}\right) \\
r \operatorname{Tr}\left\{G_{k}^{T}\left(2 P_{k} \tilde{x} \tilde{x}^{T} P_{k}+\tilde{x}^{T} P_{k} \tilde{x} P_{k}\right) G_{k}\right\} & \leq 3 r n \sqrt{n}\left\|P_{k}\right\|^{2}\|\tilde{x}\|^{2}\left\|G_{k}\right\|^{2} \\
& \leq \frac{3}{2} r n \sqrt{n} v_{0}\left\|P_{k}\right\|^{4}\|\tilde{x}\|^{4}+\frac{3 r n \sqrt{n}}{2 v_{0}} \bar{\sigma}^{2}
\end{aligned}
$$

where $v_{0}$ is a positive designed scalar.

According to (17) and (19), we have:

$$
\mathcal{L} V_{k 0} \leq-\Xi\|\tilde{x}\|^{4}+D_{0}
$$

where $\Xi=r \lambda_{\min }\left(P_{k}\right) \lambda_{\min }\left(Q_{k}\right)-\frac{3 r}{2} v_{0}^{\frac{4}{3}}\left\|P_{k}\right\|^{\frac{8}{3}}-\frac{3}{2} r n \sqrt{n} v_{0}\left\|P_{k}\right\|^{4}$ and $D_{0}=\frac{r}{2 v_{0}^{4}}\left(\theta^{2}+\varepsilon_{0}^{4}\right)+$ $\frac{3}{2 v_{0}} r n \sqrt{n} \bar{\sigma}^{2}$.

Step 1. Consider the stochastic Lyapunov function below:

$$
V_{k 1}=V_{k 0}+\frac{1}{4} \xi_{1}^{4}
$$

According to (13)-(15), we have:

$$
d \xi_{1}=\left(\xi_{2}+\vartheta_{2}+\alpha_{2 d}+\tilde{x}_{2}-\dot{y}_{d}-\dot{\vartheta}_{1}\right) d t .
$$

By combining (21) and (22), we obtain:

$$
\mathcal{L} V_{k 1}=-\Xi\|\tilde{x}\|^{4}+D_{0}+\tilde{\zeta}_{1}^{3}\left(\xi_{2}+\vartheta_{2}+\alpha_{2 d}+\tilde{x}_{2}-\dot{y}_{d}-\dot{\vartheta}_{1}\right) .
$$

Under Young's inequality, we have:

$$
\begin{gathered}
\xi_{1}^{3} \xi_{2} \leq \frac{3}{4} v_{11}^{\frac{4}{3}} \xi_{1}^{4}+\frac{1}{4 v_{11}^{4}} \xi_{2}^{4}, \\
\xi_{1}^{3} \tilde{x}_{2} \leq \frac{3}{4} v_{12}^{\frac{4}{3}} \xi_{1}^{4}+\frac{1}{4 v_{12}^{4}}\|\tilde{x}\|^{4},
\end{gathered}
$$

where $v_{1 j}(j=1,2)$ are positive designed scalars.

Substituting (24) and (25) into (23) leads to:

$$
\begin{aligned}
\mathcal{L} V_{k 1} \leq & -\left(\Xi-\frac{1}{4 v_{12}^{4}}\right)\|\tilde{x}\|^{4}+\xi_{1}^{3}\left(\frac{3}{4} v_{11}^{\frac{4}{3}} \xi_{1}+\vartheta_{2}+\alpha_{2 d}-\alpha_{1}+\alpha_{1}\right. \\
& \left.+\frac{3}{4} v_{12}^{\frac{4}{3}} \xi_{1}-\dot{y}_{d}-\dot{\vartheta}_{1}\right)+\frac{1}{4 v_{11}^{4}} \xi_{2}^{4}+D_{0} .
\end{aligned}
$$

In order to eliminate the traditional problem of the "explosion of terms", we introduce the TD technique in [20] to help the control design. Next, we let the virtual control function $\alpha_{1}$ pass through the following TD:

$$
\left\{\begin{array}{l}
\dot{\alpha}_{2 d}=\chi_{2} \\
\dot{\chi}_{2}=-R_{2}^{2}\left[a_{21} \sinh \left(l_{21}\left(\alpha_{2 d}-\alpha_{1}\right)\right)+a_{22} \sinh \left(l_{22} \chi_{2} / R_{2}\right)\right],
\end{array}\right.
$$

where $R_{2}, a_{21}, a_{22}, l_{21}, l_{22}$ are positive arguments; $\alpha_{2 d}$ is the estimate of $\alpha_{1}$ with $s_{2 d}=\alpha_{2 d}-\alpha_{1}$ denoting the generated estimation error. Via [20], the boundedness of the error can be ensured by a suitable choice of the TDs' design parameters. Thus, there exists a positive constant $s_{M}$ such that $\left|s_{2 d}\right| \leq s_{M}$. 
Remark 4. It should be emphasized that, despite the generated estimation error $s_{2 d}$ being bounded, it still will have an influence on the control performance to some extent. Thus, it is reasonable and necessary to establish the compensating signals and the corresponding new tracking errors (15) for System (3).

Now, the compensating signal $\vartheta_{1}$ is established as:

$$
\dot{\vartheta}_{1}=-\kappa_{1} \vartheta_{1}+\vartheta_{2}+\left(\alpha_{2 d}-\alpha_{1}\right),
$$

with $\vartheta(0)=0$ for $t \in\left[0, T_{1}\right]$. This is a time-varying linear filter with bounded input $s_{2 d}=\alpha_{2 d}-\alpha_{1}$.

Then, the following virtual control input is constructed:

$$
\alpha_{1}=-\kappa_{1} z_{1}-\frac{3}{4} v_{11}^{\frac{4}{3}} \xi_{1}-\frac{3}{4} v_{12}^{\frac{4}{3}} \xi_{1}+\dot{y}_{d} .
$$

Substituting them into (26) results in:

$$
\mathcal{L} V_{k 1} \leq-\left(\Xi-\frac{1}{4 v_{12}^{4}}\right)\|\tilde{x}\|^{4}-\kappa_{1} \xi_{1}^{4}+\frac{1}{4 v_{11}^{4}} \xi_{2}^{4}+D_{0} .
$$

Step 2. Define the stochastic Lyapunov function as:

$$
V_{k 2}=V_{k 1}+\frac{1}{4} \xi_{2}^{4}+\frac{\tilde{\theta}^{2}}{2 \gamma}
$$

in which $\theta=\max _{k \in \mathfrak{L}}\left\{\left\|W_{k, 1}^{T}\right\|^{2}\right\}$ is an unknown constant, $\tilde{\theta}=\theta-\hat{\theta}$.

According to (14) and (15), we have:

$$
d \xi_{2}=\left(u_{k}+l_{k, 2} \tilde{x}_{1}-\dot{\alpha}_{2 d}-\dot{\vartheta}_{2}\right) d t .
$$

By combining (31) and (32), we obtain:

$$
\mathcal{L} V_{k 2}=\mathcal{L} V_{k 1}+\xi_{2}^{3}\left(u_{k}+l_{k, 2} \tilde{x}_{1}-\dot{\alpha}_{2 d}-\dot{\vartheta}_{2}\right)-\frac{1}{\gamma} \tilde{\theta} \dot{\hat{\theta}} .
$$

In light of the above description, it yields:

$$
\xi_{2}^{3} u_{k}=\xi_{2}^{3}\left(v_{c k}+\sigma_{k}^{\prime}\left(v_{k}\right)-v_{\phi k}+\omega_{k}\right),
$$

then the FLS is utilized to develop the control issue on the dead-zone input:

$$
\begin{aligned}
\xi_{2}^{3}\left(\sigma_{k}^{\prime}\left(v_{k}\right)+\omega_{k}\right) & =\xi_{2}^{3}\left(W_{k, 1}^{T} S_{k, 1}+\delta_{k, 1}+\omega_{k}\right), \\
& \leq \frac{1}{2 a^{2}} \xi_{2}^{6} \theta S_{k, 1}^{T} S_{k, 1}+\frac{a^{2}}{2}+\frac{3}{4} \xi_{2}^{4}+\frac{1}{4} \bar{l}^{4} \\
& \leq \frac{1}{2 a^{2}} \xi_{2}^{6} \theta+\frac{a^{2}}{2}+\frac{3}{4} \xi_{2}^{4}+\frac{1}{4} \bar{l}^{4},
\end{aligned}
$$

where $\left|\delta_{k, 1}+\omega_{k}\right| \leq \bar{l}$, and the property of $0<S_{k, 1}^{T} S_{k, 1} \leq 1$ is used here.

Similarly, we have:

$$
\xi_{2}^{3} l_{k, 2} \tilde{x}_{1} \leq \frac{3}{4} v_{22}^{\frac{4}{3}} l_{k, 2}^{\frac{4}{3}} \xi_{2}^{4}+\frac{1}{4 v_{22}^{4}}\|\tilde{x}\|^{4},
$$

where $v_{22}$ is a positive designed scalar. 
It can be obtained by simple calculation and sorting that:

$$
\begin{aligned}
\mathcal{L} V_{k 2}= & -\left(\Xi-\sum_{j=1}^{2} \frac{1}{4 v_{j 2}^{4}}\right)\|\tilde{x}\|^{4}-\kappa_{1} \xi_{1}^{4}+\xi_{2}^{3}\left(\frac{1}{4 v_{11}^{4}} \xi_{2}+\frac{3}{4} v_{22}^{\frac{4}{3}} l_{k, 2}^{\frac{4}{3}} \xi_{2}+v_{c k}-\dot{\alpha}_{2 d}\right. \\
& \left.-\dot{\vartheta}_{2}\right)+\xi_{2}^{3}\left(\frac{1}{2 a^{2}} \xi_{2}^{3} \theta+\frac{3}{4} \xi_{2}-v_{\phi k}\right)-\frac{1}{\gamma} \tilde{\theta} \dot{\hat{\theta}}+D_{0}+\frac{a^{2}}{2}+\frac{1}{4} \bar{l}^{4} .
\end{aligned}
$$

On the same principle, the following compensating signals $\vartheta_{2}$ are designed and taken into account:

$$
\dot{\vartheta}_{2}=-\kappa_{2} \vartheta_{2}
$$

Then, substituting the following constructed actual control input:

$$
\begin{aligned}
& v_{c k}=-\underline{\kappa}_{k, 2} z_{2}-\frac{1}{4 v_{11}^{4}} \xi_{2}-\frac{3}{4} v_{22}^{\frac{4}{3}} 2_{k, 2}^{\frac{4}{3}} \xi_{2}+\dot{\alpha}_{2 d}, \\
& v_{\phi k}=\bar{\kappa}_{k, 2} \xi_{2}+\frac{3}{4} \xi_{2}+\frac{1}{2 a^{2}} \xi_{2}^{3} \hat{\theta},
\end{aligned}
$$

and the adaptive law into (37):

$$
\dot{\hat{\theta}}=\frac{\gamma}{2 a^{2}} \xi_{2}^{6}-\beta \hat{\theta}
$$

we have:

$$
\mathcal{L} V_{k 2}=-\left(\Xi-\sum_{j=1}^{2} \frac{1}{4 v_{j 2}^{4}}\right)\|\tilde{x}\|^{4}-\sum_{j=1}^{2} \kappa_{j} \xi_{j}^{4}-\frac{\beta}{2 \gamma} \tilde{\theta}^{2}+D,
$$

where $D=D_{0}+\frac{a^{2}}{2}+\frac{1}{4} \bar{l}^{4}+\frac{\beta}{2 \gamma} \theta^{2}$ and $\kappa_{2} \leq \min \left\{\underline{\kappa}_{k, 2}+\bar{\kappa}_{k, 2}\right\}$.

\subsection{Stability Analysis}

The properties of the main result are presented in Theorem 1.

Theorem 1. For the ship heading control system (3) with asymmetric dead-zone, via ADT $\tau_{a}>\left(\log \mu / p_{2}\right)$ with $\mu=\max \left\{\frac{\lambda_{\max }\left(P_{k}\right)}{\lambda_{\min }\left(P_{q}\right)}, k, q \in \mathfrak{L}\right\}$ and $\sigma(t)$, the convergence of $z_{1}$ is obtained under the proposed control scheme (29) and (39)-(41); meanwhile, the resulting signals are bounded in the probability.

Before showing the analysis of Theorem 1, the following Lemma 3 is given to develop the proof, which can easily verify that the constructed compensating signals (28) and (38) are bounded.

Lemma 3. The system defined in (28) and (38) has states bounded by $\|\vartheta(t)\| \leq \frac{s_{M}}{2 \kappa_{0}}(1-$ $\left.e^{-2 \kappa_{0}\left(t-T_{1}\right)}\right)$, then:

$$
\lim _{t \rightarrow \infty}\|\vartheta(t)\| \leq \frac{s_{M}}{2 \kappa_{0}}
$$

where $\kappa_{0}=\frac{1}{2} \min _{i}\left(\kappa_{i}-1\right)$.

Remark 5. The relevant proof is easily confirmed and thus is omitted here.

Next, we begin the proof of Theorem 1 via the ADT approach. 
Proof. Choosing appropriate parameters $r, v_{0}, v_{i 2}(i=1,2)$ such that:

$$
\Xi-\sum_{i=1}^{3} \frac{1}{4 v_{i 2}^{4}} \geq c_{0}>0
$$

defining:

$$
\begin{aligned}
& p_{2}=\min _{k \in \mathfrak{L}}\left\{4 \kappa_{i}, \frac{2 c_{0}}{r \lambda_{\max }^{2}\left(P_{k}\right)}, \beta, i=1,2\right\}, \\
& p_{1}=\max _{k \in \mathfrak{L}}\left\{\frac{r}{2 v_{0}^{4}}\left(\theta^{2}+\varepsilon_{0}^{4}\right)+\frac{3}{2 v_{0}} r n \sqrt{n} \bar{\sigma}^{2}+\frac{a^{2}}{2}+\frac{1}{4} \bar{l}^{4}+\frac{\beta}{2 \gamma} \theta^{2}\right\}>0,
\end{aligned}
$$

and defining $V_{k}(X)$ as the whole stochastic Lyapunov with $X=\left[\tilde{x}^{T}, \xi^{T}, \tilde{\theta}\right]$, then (42) can be rewritten as:

$$
\mathcal{L} V_{k}(X) \leq p_{1}-p_{2} V_{k} .
$$

Furthermore, it is easily obtained that $\bar{o}(\|X\|) \leq V_{k}(X) \leq \underline{o}(\|X\|)$.

Next, the following piecewise differentiable function is considered to develop the analysis:

$$
\mathcal{W}(t)=e^{p_{2} t} V_{\sigma(t)}(X(t)),
$$

and then, for $k, q \in \mathfrak{L}$, it follows from the fact $V_{k}(X(t)) \leq \mu V_{q}(X(t))$, during $\left[t_{k}, t_{k+1}\right)$, that one furthermore obtains:

$$
E\left\{\mathcal{W}\left(t_{k+1}\right)\right\} \leq \mu\left[E\left\{\int_{t_{k}}^{t_{k+1}} p_{1} e^{p_{2} t} d t\right\}+E\left\{\mathcal{W}\left(t_{k}\right)\right\}\right]
$$

Then, integrating (47), we have:

$$
\begin{aligned}
E\left\{\mathcal{W}\left(T^{-}\right)\right\} \leq & {\left[E\{\mathcal{W}(0)\}+E\left\{\sum_{k=0}^{N_{\sigma}(T, 0)-1} \mu^{-k} \int_{t_{k}}^{t_{k+1}} p_{1} e^{p_{2} t} d t\right\}\right.} \\
& \left.+E\left\{\mu^{-N_{\sigma}(T, 0)} \int_{t_{N_{\sigma}(T, 0)}^{T}}^{T} p_{1} e^{p_{2} t} d t\right\}\right] \mu^{N_{\sigma}(T, 0)} .
\end{aligned}
$$

Then, $\tau_{a}>\left(\log \mu / p_{2}-\delta\right)$ can be obtained by considering $0<\delta<p_{2}-\left(\log \mu / \tau_{a}\right)$ and ADT $\tau_{a}>\left(\log \mu / p_{2}\right)$. Combining it with (10), we have $N_{\sigma(t)}\left(T_{2}, T_{1}\right) \leq \frac{\left(p_{2}-\delta\right)\left(T_{2}-T_{1}\right)}{\log \mu}+N_{0}$.

Taking $k$ to be $0,1, \cdots, N_{\sigma}(T, 0)$, the following hold:

$$
E\left\{\int_{t_{k}}^{t_{k+1}} p_{1} e^{p_{2} t} d t\right\} \leq E\left\{e^{\left(p_{2}-\delta\right) t_{k+1}} \int_{t_{k}}^{t_{k+1}} p_{1} e^{\delta t} d t\right\}
$$

and:

$$
E\left\{\mathcal{W}\left(T^{-}\right)\right\} \leq E\left\{\mathcal{W}(0) \mu^{N_{\sigma}(T, 0)}\right\}+E\left\{\mu^{1+N_{0}} e^{\left(p_{2}-\delta\right) T} \int_{0}^{T} p_{1} e^{\delta t} d t\right\}
$$

Considering $\mathcal{W}(t)$ yields:

$$
\begin{aligned}
E\{\bar{o}(\|X(T)\|)\} & \leq E\left\{V_{\sigma\left(T^{-}\right)}\left(X\left(T^{-}\right)\right)\right\} \\
& \leq e^{N_{0} \log \mu} e^{\left(\frac{\log \mu}{\tau_{a}}-p_{2}\right) T} E\{\underline{o}(\|X(0)\|)\}+\mu^{1+N_{0}} \frac{p_{1}}{\delta} .
\end{aligned}
$$


The following (52) holds:

$$
\frac{1}{\mu^{1+N_{0}}} E\left\{V_{\sigma\left(T^{-}\right)}\left(X\left(T^{-}\right)\right)\right\} \leq \frac{1}{\mu^{1+N_{0}}} e^{N_{0} \log \mu} E\{\underline{o}(\|X(0)\|)\}+\frac{p_{1}}{\delta} .
$$

where $\tau_{a}>\left(\log \mu / p_{2}\right)$ and $0<e^{-\delta(T-t)} \leq 1$ are used. Therefore, according to Lemma 2, the boundedness can be concluded.

Furthermore, for $\forall T>0$, we obtain:

$$
\frac{1}{4} E\left\{\left|\xi_{1}^{4}(T)\right|\right\} \leq e^{N_{0} \log \mu} e^{\left(\frac{\log \mu}{\tau_{a}}-p_{2}\right) T} E\{\underline{o}(\|X(0)\|)\}+\mu^{1+N_{0}} \frac{p_{1}}{\delta}\left(1-e^{-\delta T}\right),
$$

considering that $\tau_{a}>\left(\log \mu / p_{2}\right)$,

$$
\lim _{T \rightarrow \infty} E\left\{\left|\xi_{1}^{4}(T)\right|\right\} \leq 4 \mu^{1+N_{0}} \frac{p_{1}}{\delta} \leq \epsilon^{4},
$$

where $\epsilon$ is a positive constant, and then, in accordance with (15) and Lemma 3, we can obtain:

$$
\lim _{T \rightarrow \infty}\left|z_{1}\right| \leq \epsilon+\frac{s_{M}}{2 \kappa_{0}}
$$

This completes the proof.

\section{Simulation Study and Discussion}

The switched control of the above ship heading control system (3) is governed by the speed as:

$$
\sigma(t)= \begin{cases}1, & \text { low speed } \\ 2, & \text { medium speed } \\ 3, & \text { top speed }\end{cases}
$$

Correspondingly, the parameters of the nonlinear ship heading control system from $[17,35]$ were used, namely $T_{1}=30 \mathrm{~s}, K_{1}=32 \mathrm{~s}^{-1}, \tau_{1}=40 \mathrm{~s}^{2} ; T_{2}=63.69 \mathrm{~s}, K_{2}=11.4 \mathrm{~s}^{-1}$, $\tau_{2}=30 \mathrm{~s}^{2} ; T_{3}=80.47 \mathrm{~s}, K_{3}=5.1 \mathrm{~s}^{-1}, \tau_{3}=25 \mathrm{~s}^{2}$. For the stochastic noise, $g_{1}=0.5 x_{1} \sin \left(x_{2} x_{3}\right), g_{2}=0.25 x_{1}^{2} x_{2} \cos \left(x_{2}\right)$, and $g_{3}=0.1 x_{1} x_{3}$ were chosen.

For the dead-zone, we assumed that:

$$
\begin{gathered}
u_{1}=\Gamma_{1}\left(v_{1}\right)= \begin{cases}1\left(v_{1}-2\right), & v_{1} \geq 2 \\
0, & -3<v_{1}<2 \\
2\left(v_{1}+3\right), & v_{1} \leq-3\end{cases} \\
u_{2}=\Gamma_{2}\left(v_{2}\right)= \begin{cases}0.8\left(v_{2}-3.5\right), & v_{2} \geq 3.5 \\
0, & -2<v_{2}<35 \\
1\left(v_{2}+2\right), & v_{2} \leq-2\end{cases} \\
u_{3}=\Gamma_{3}\left(v_{3}\right)= \begin{cases}1\left(v_{3}-4.5\right), & v_{3} \geq 4.5 \\
0, & -4<v_{3}<4.5 \\
1.5\left(v_{3}+4\right), & v_{3} \leq-4\end{cases}
\end{gathered}
$$

The initial condition $\left[x_{1}(0), x_{2}(0), \hat{x}_{1}(0), \hat{x}_{2}(0), \hat{\theta}(0)\right]^{T}=[0.01,0.01,0.01,0.01,0.01]^{T}$ was set to run the simulation. What is more, we set $\kappa_{1}=1, \kappa_{2}=0.1, \underline{\kappa}_{12}=0.5, \underline{\kappa}_{22}=0.2$, $\underline{\kappa}_{32}=\bar{\kappa}_{12}=\bar{\kappa}_{22}=1, \bar{\kappa}_{32}=2, \gamma=0.1, a=2, \beta=1$, and $v_{11}=1, v_{12}=5, v_{22}=10, r=0.5$. 
Constants $l_{1,1}=4, l_{2,1}=2, l_{3,1}=2, l_{1,2}=6, l_{2,2}=10$, and $l_{3,2}=8$ were chosen such that the matrices $A_{1}, A_{2}, A_{3}$ were Hurwitz. Then, by choosing $Q_{1}=Q_{2}=Q_{3}=I_{2}$, we have:

$$
P_{1}=\left[\begin{array}{cc}
0.8750 & -0.5000 \\
-0.5000 & 0.4792
\end{array}\right], P_{2}=\left[\begin{array}{cc}
2.7500 & -0.5000 \\
-0.5000 & 0.3750
\end{array}\right], P_{3}=\left[\begin{array}{cc}
2.2500 & -0.5000 \\
-0.5000 & 0.4062
\end{array}\right] \text {. }
$$

then we can compute $\mu=\max \{2,2.347\}=2.347$. Then, $\tau_{a}=13>(\log 2.347 / 0.067)$ is obtained from Theorem 1.

The obtained results are described in Figures 1-15. Figure 1 clearly indicates the heading tracking performance of System (3), and it can be seen that the system output follows the desired tracking signal $y_{d}=10 \sin (0.08 t)$ very well under the proposed TDbased control method. Figures 2 and 3 give the system states and the corresponding observer states under the switched state observers, which shows that the unmeasured system states can still be well estimated by the designed switched state observers when the unknown switched actuator dead-zone inputs (57)-(59) are presented in the ship heading control system (3). The adaptive law is depicted in Figure 4. Figure 5 indicates the switched controllers under the switching signal described by Figure 6, which satisfies the calculated ADT $\tau_{a}$. All of this means that the desired control result can be fulfilled very well via the developed control algorithm.

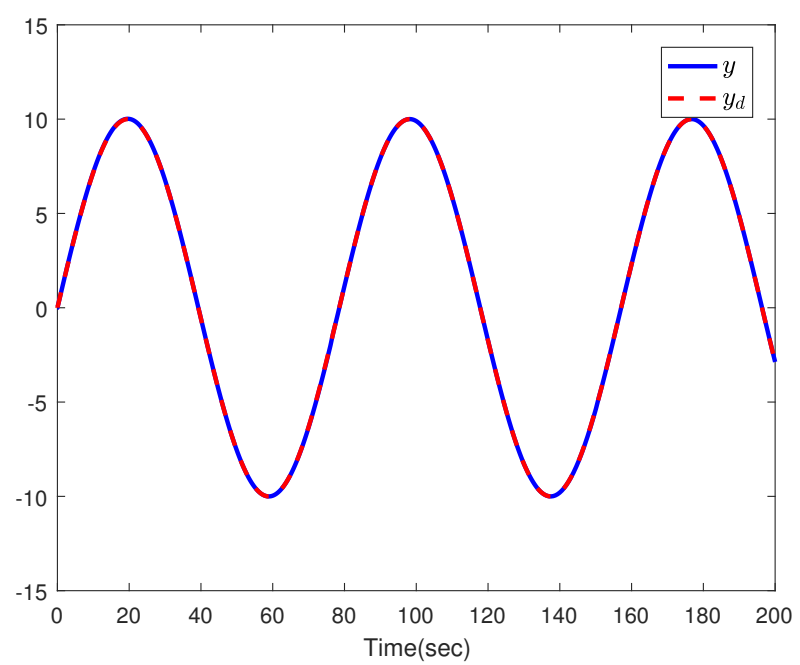

Figure 1. Tracking effect of System (3).

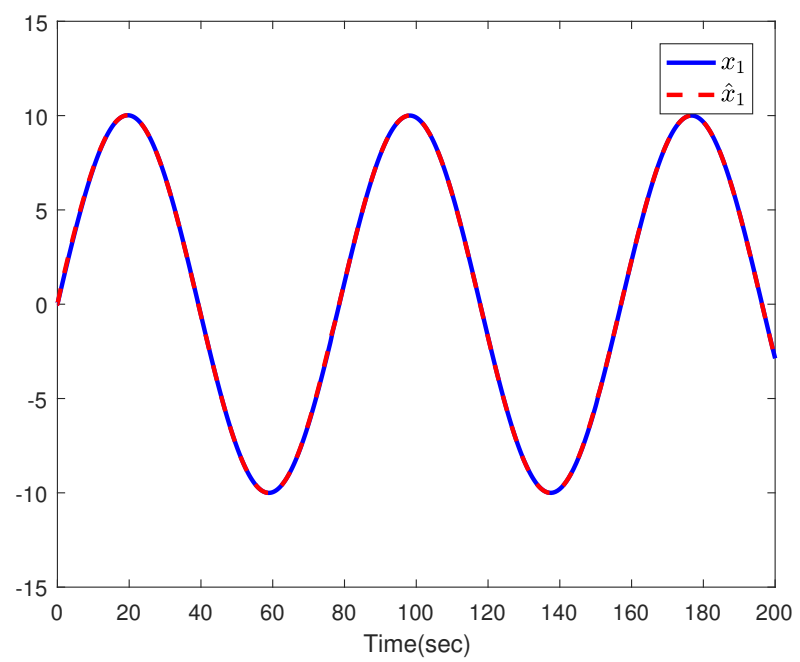

Figure 2. Responses of states $x_{1}$ and $\hat{x}_{1}$. 


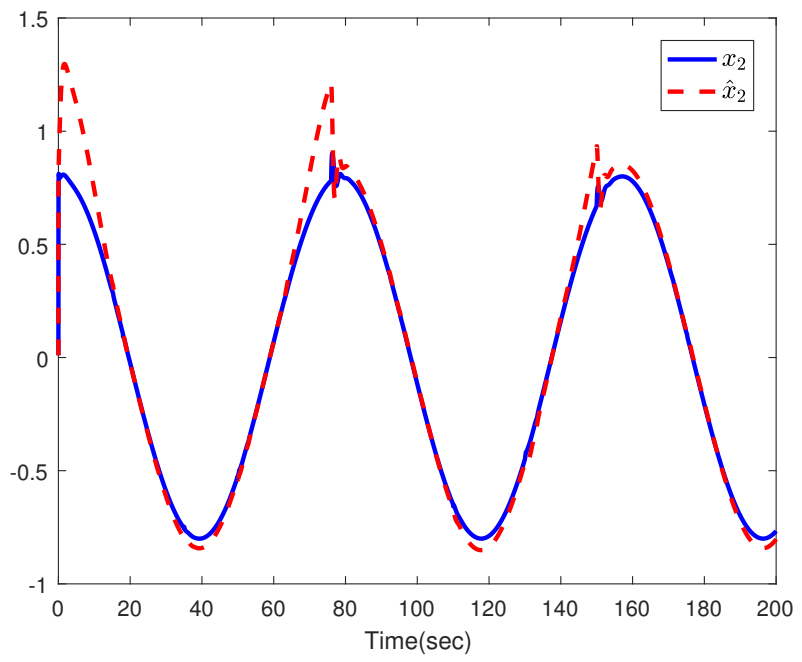

Figure 3. Responses of states $x_{2}$ and $\hat{x}_{2}$.

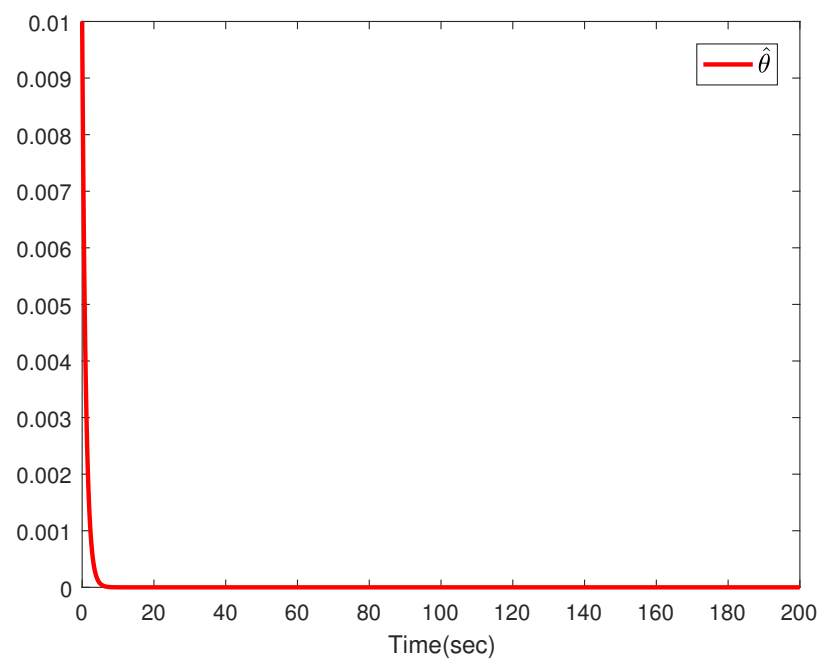

Figure 4. Adaptive law.

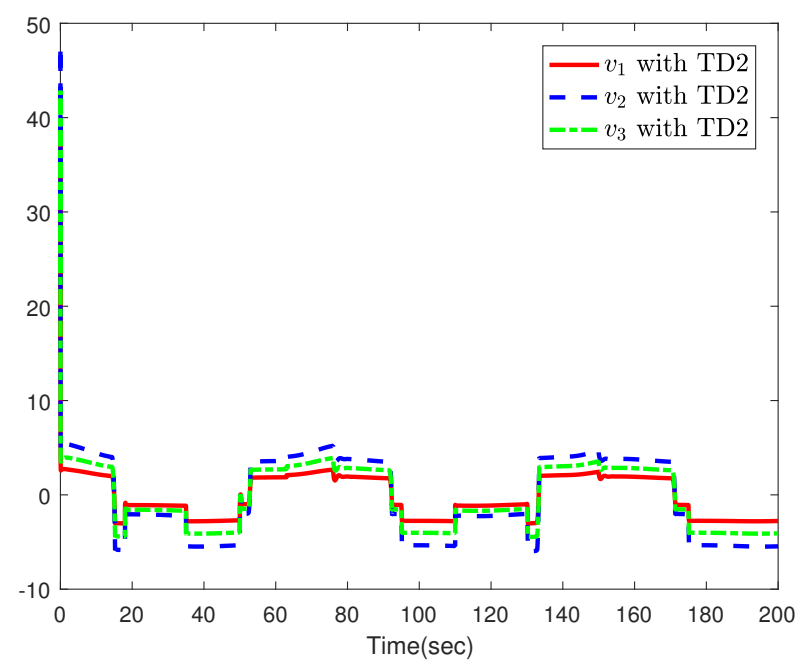

Figure 5. Control effect of System (3) under TD2. 


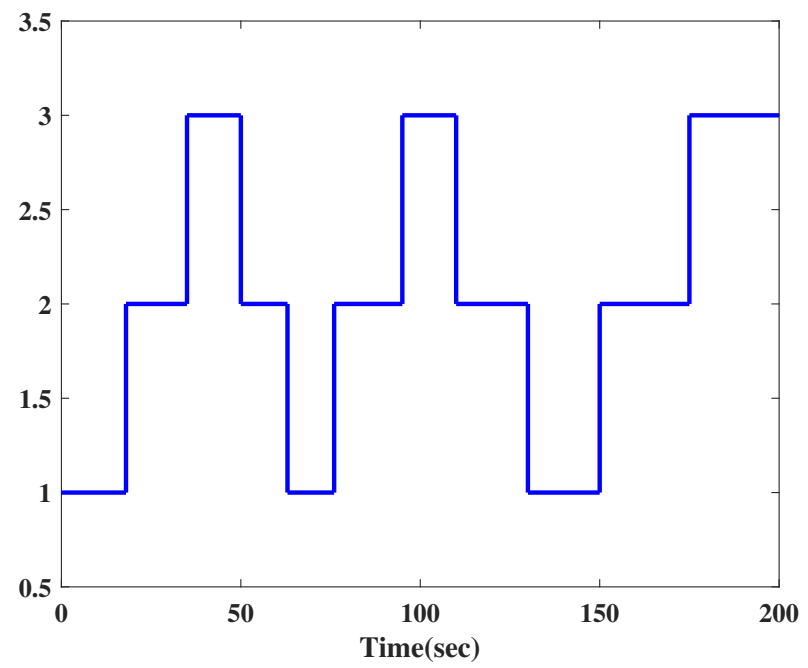

Figure 6. Switching signal.

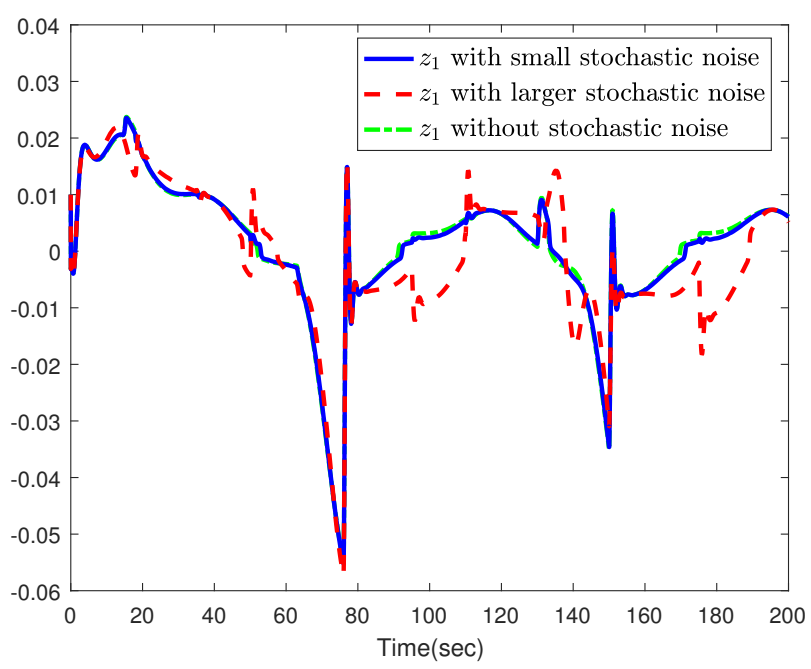

Figure 7. Influence of stochastic noise on the tracking effect under TD2.

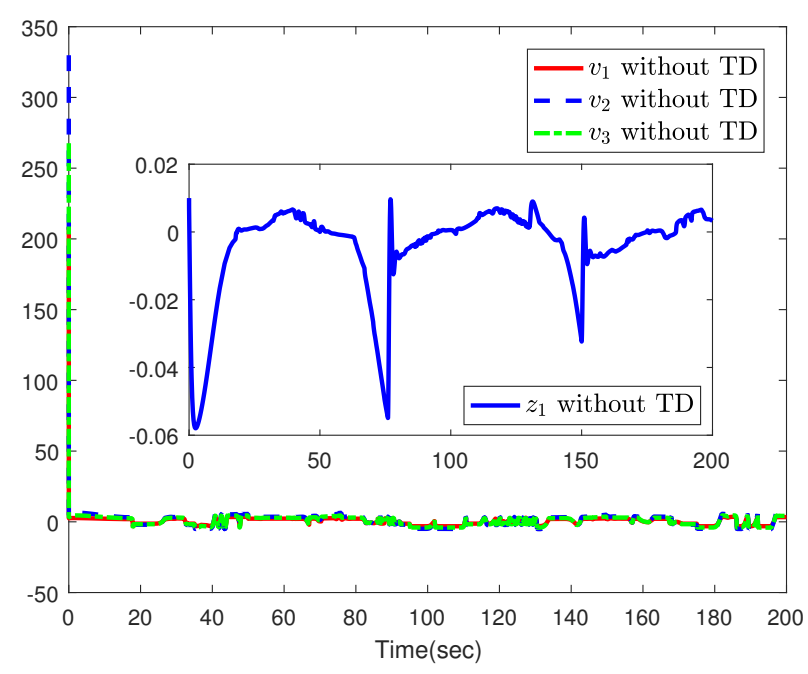

Figure 8. Control effect of System (3) without TD. 


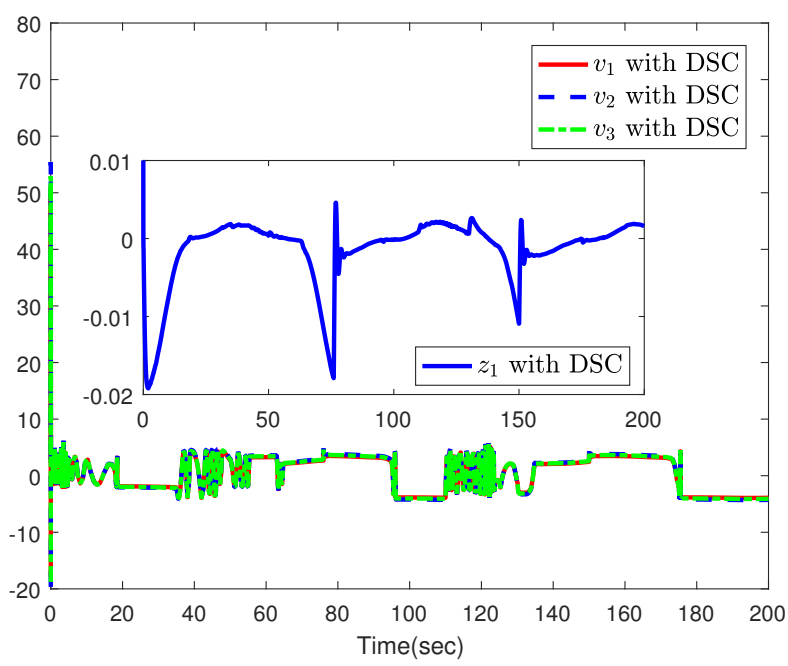

Figure 9. Control effect of System (3) with DSC.

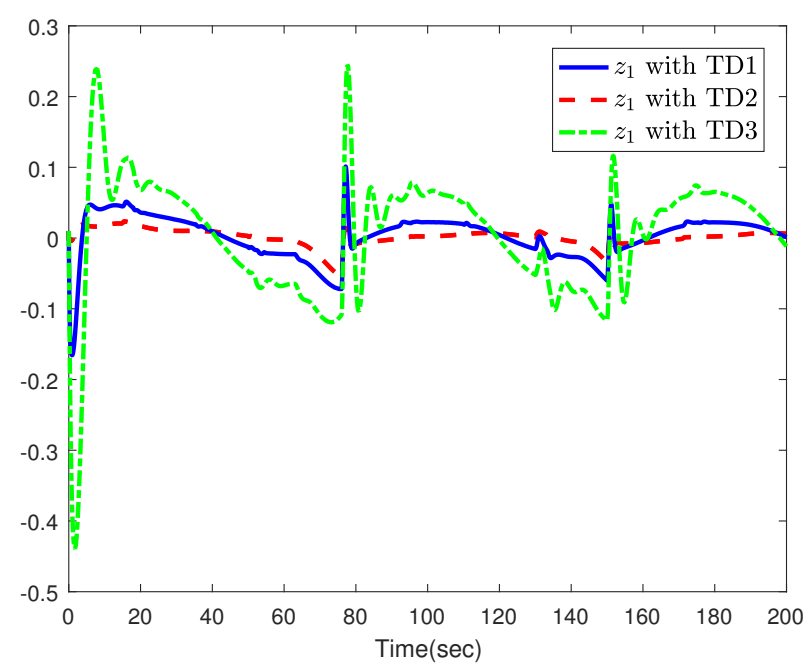

Figure 10. Tracking effect of System (3) with different TDs.

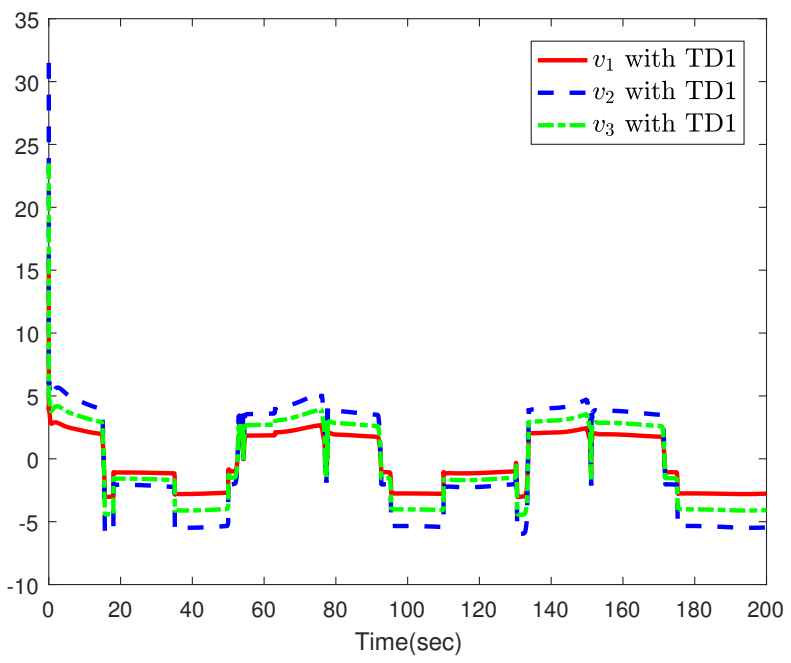

Figure 11. Control effect of System (3) under TD1. 


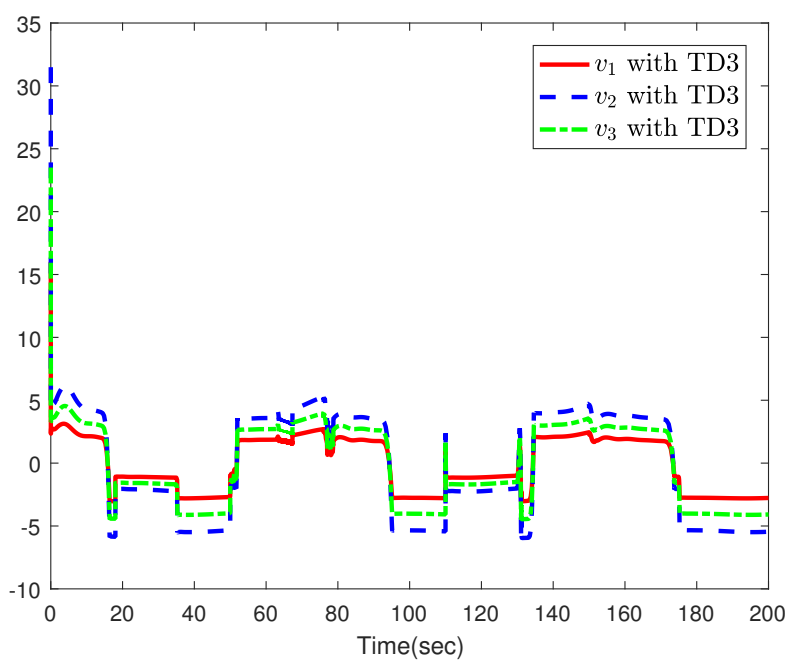

Figure 12. Control effect of System (3) under TD3.

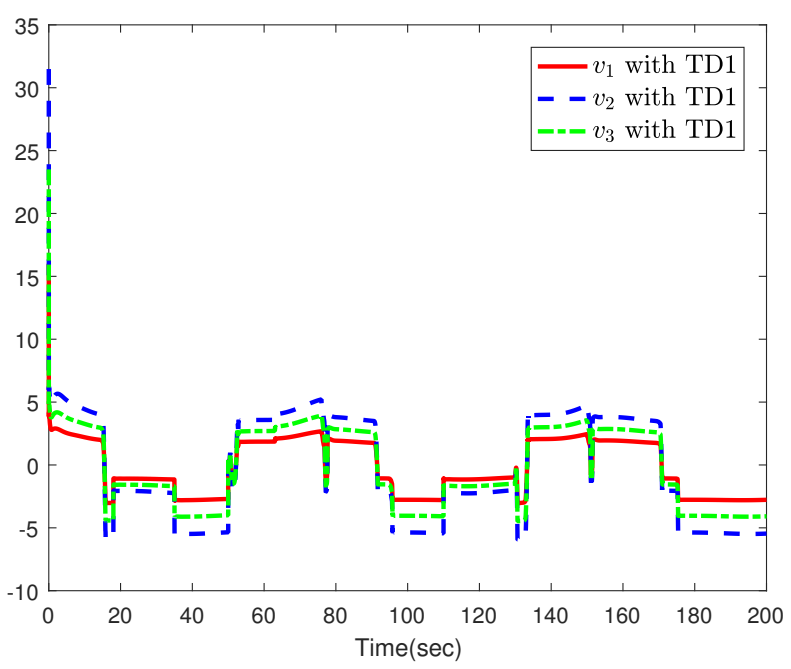

Figure 13. Control effect of System (3) without stochastic noise under TD1.

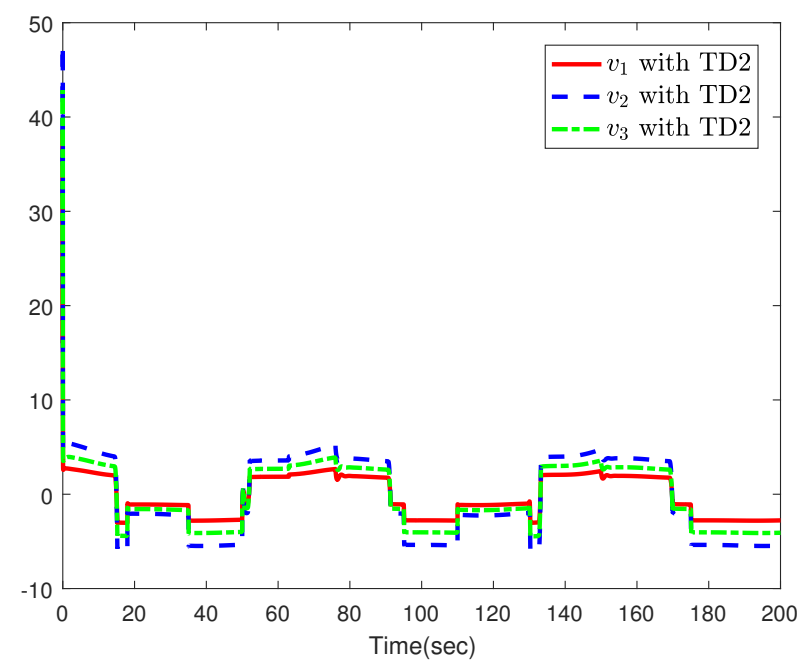

Figure 14. Control effect of System (3) without stochastic noise under TD2. 


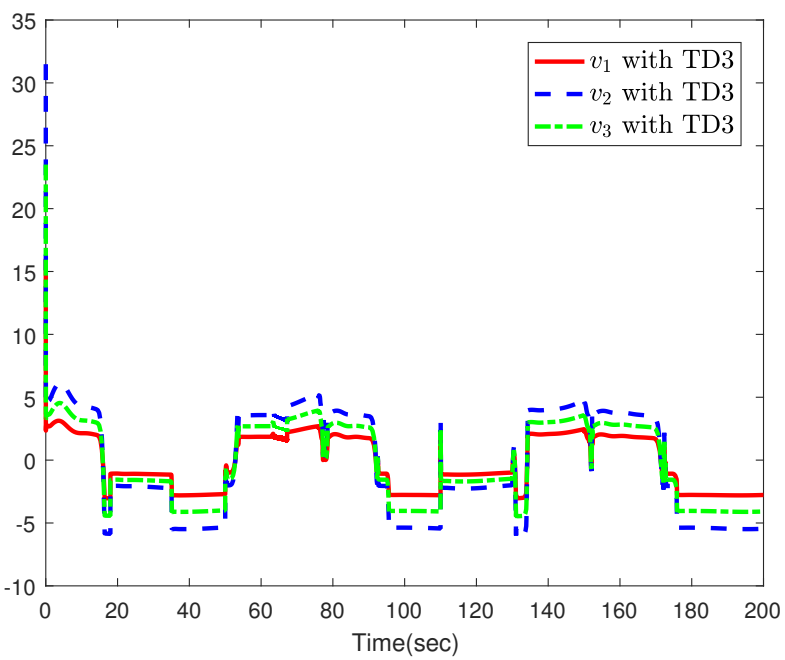

Figure 15. Control effect of System (3) without stochastic noise under TD3.

In order to further exhibit the developed work, we performed some comparison tests to justify its implementation under the same conditions:

(i) The influence of stochastic noise on heading control:

This work discusses the ship heading tracking with stochastic noise, which is more in line with the actual navigation environment. In order to illustrate the influence of stochastic noise more clearly and intuitively, the corresponding test results without/with different levels of stochastic noises are presented. In Figure 7, the heading tracking control results of the ship control system for three cases are described under the developed control algorithm: the control system (3) with small stochastic noise, the control system (3) with larger stochastic noise, and the control system (3) without stochastic noise, respectively. By comparison, it can be seen that the stochastic noise has a certain effect on the heading tracking control in the actual navigation environment. Therefore, it is necessary to consider the stochastic noise in the ship control when establishing the ship heading system mathematical model and then carry out the heading tracking control;

(ii) The comparison of the TD method with other methods:

To better illustrate the impact of the TD method on the control performance, we performed the following experimental tests, respectively.

Firstly, the method without the TD feature was applied to control the ship heading system (3), and the corresponding control result of the heading tracking with controllers is shown in Figure 8, which indicates that the controllers developed without the TD feature can still provide effective heading tracking control performance. However, it should be noted that there is the undesired problem of the "explosion of terms" occurring in the control design. The structure of such a heading control scheme is thus complicated, and the term of $\sum_{j=0}^{1} \frac{\partial \alpha_{1}}{y_{d}^{(j)}} y_{d}^{(j+1)}$ is involved, while the knowledge of $y_{d}(t)$ and its first two-order time derivatives $\dot{y}_{d}(t), \ddot{y}_{d}(t)$ is needed; therefore, more computational work is required, which is not conducive to practical engineering applications.

Secondly, the commonly used method of dealing with the "explosion of terms", the DSC method, was also employed to carry out the heading tracking control for System (3), and the corresponding tracking control result is described in Figure 9. In this way, the problem of the "explosion of terms" was avoided successfully; however, in the commonly used DSC method, the boundary $s_{2 d}=\alpha_{2 d}-\alpha_{1}$ results from the filter are not considered and compensated, which will have a certain influence on the control performance. Our TD-based control method considers the boundary $s_{2 d}$ and introduces the compensating signals (28) and (38) to compensate this.

From the above results, we can see that, under the same conditions, both of these methods can develop the heading tracking control of System (3) and achieve the control 
goal successfully, but the TD method can give a better control performance and is more conducive to practical engineering applications;

(iii) The effect of the TD feature on control performance:

To illustrate the effect of the TD feature on the control performance, three TDs were chosen in the following experimental tests, defining: TD1: $R_{2}=10, a_{21}=1.5, a_{22}=5$, $l_{21}=l_{22}=1$; TD2: $R_{2}=100, a_{21}=5, a_{22}=10, l_{21}=l_{22}=0.5$; TD3: $R_{2}=1$, $a_{21}=a_{22}=0.5, l_{21}=l_{22}=5$, respectively; the corresponding comparison results are exhibited in Figures 10-15.

Firstly, Figure 10 clearly shows the heading tracking performance for System (3) with different TDs. This is followed by the corresponding controller performances obtained in Figures 5, 11 and 12. Furthermore, we illustrate the effect of the TD feature on the controller performance when stochastic noise is not present in System (3), and the test results are given in Figures 13-15. From the above comparison results, it follows that the TD feature will have a certain effect on controller performance for the ship heading system (3) whether there is stochastic noise or not. By comparison, we can conclude that, by the appropriate parameter selection of the TD, the desired heading tracking performance and control performance can be ensured.

From the above experiment results, we can obtain the following conclusions:

(1) Stochastic noise in complex sea conditions does have an impact on the system performance, especially when there is a huge stochastic effect resulting from excessive wind and waves, and it will have a terrible impact on the control system. Therefore, it is of great practical significance to consider the stochastic noise in system modeling and study the related control issues for safe navigation;

(2) The novel TD-based adaptive heading tracking control scheme has a simple structure, and it only needs the knowledge of $y_{d}(t)$ and its one-order time derivative $\dot{y}_{d}(t)$, while the drawback of the "explosion of terms" is cleverly prevented by taking the boundary $s_{2 d}=\alpha_{2 d}-\alpha_{1}$ in the designed compensating signals into account; thus, the computational work is reduced greatly, which is very conducive to practical ship control;

(3) The developed TD-based control scheme can achieve a good control effect by means of proper parameter selections. However, the parameter tuning is a nontrivial and tedious task. In order to obtain the desired heading control performance, large $R_{2}, a_{21}, a_{22}$ and small $l_{21}, l_{22}$ are needed, but it should be noted that, too large $R_{2}, a_{21}, a_{22}$ and too small $l_{21}, l_{22}$ will result in bad heading tracking and controller convergence.

\section{Conclusions}

Switched adaptive heading control under stochastic noise and an unknown dead-zone was considered. The ship control model under stochastic noise was established, and the tracking controller was constructed. Via the incorporation of switched state observers, the switched adaptive output feedback tracking control tactic was proposed. The TD technique was innovatively introduced to dispose of the "explosion of terms" occurring in ship control. Finally, a theoretical analysis verified the control model.

Author Contributions: Conceptualization and methodology, Y.L.; validation and formal analysis, Y.L. and D.M.; writing—original draft preparation, Y.L., R.W. and Y.Z.; funding acquisition, Y.L. All authors have read and agreed to the published version of the manuscript.

Funding: This work is supported by the National Natural Science Foundation of China (Grant Nos. 62103073 and 52171292) and the Fundamental Research Funds for the Central Universities (Grant No. 3132021105).

Institutional Review Board Statement: Not applicable.

Informed Consent Statement: Not applicable.

Data Availability Statement: The data presented in this study are available on request from the corresponding author.

Conflicts of Interest: The authors declare no conflict of interest. 


\section{References}

1. Yang, Y.S. Model reference fuzzy adaptive control for ship streering autopilot with uncertain nonlinear system. Shipbuild. China 2003, 44, 85-93.

2. Huang, J.S.; Wen, C.Y.; Wang, W.; Song, Y.D. Global stable tracking control of underactuated ships with input saturation. Syst. Control Lett. 2015, 85, 1-7. [CrossRef]

3. Du, J.L.; Hu, X.; Sun, Y.Q. Adaptive robust nonlinear control design for course tracking of ships subject to external disturbances and input saturation. IEEE Trans. Syst. Man Cybern. Syst. 2020, 50, 193-202. [CrossRef]

4. Wang, J.Q.; Zou, Z.J.; Wang, T. High-gain extended state observer based adaptive sliding mode path following control for an underactuated vessel sailing in restricted waters. Appl. Sci. 2019, 9, 1102. [CrossRef]

5. Jiao, R.; Chou, W.S.; Rong, Y.F.; Dong, M.J. Anti-disturbance control for quadrotor UAV manipulator attitude system based on fuzzy adaptive saturation super-twisting sliding mode observer. Appl. Sci. 2020, 10, 3719. [CrossRef]

6. Hao, L.Y.; Zhang, H.; Li, T.S.; Lin, B.; Chen, C.L.P. Fault tolerant control for dynamic positioning of unmanned marine vehicles based on T-S fuzzy model with unknown membership functions. IEEE Trans. Veh. Technol. 2021, 70, 146-157. [CrossRef]

7. Deng, Y.J.; Zhang, X.K. Event-triggered composite adaptive fuzzy output feedback control for path following of autonomous surface vessels. IEEE Trans. Fuzzy Syst. 2021, 29, 2701-2713. [CrossRef]

8. Wu, W.T.; Peng, Z.H.; Wang, D.; Liu, L.; Han, Q.L. Network-based line-of-sight path tracking of underactuated unmanned surface vehicles with experiment results. IEEE Trans. Cybern. 2021,1-11. [CrossRef]

9. Hao, L.Y.; Yu, Y.; Li, T.S.; Li, H. Quantized output feedback control for unmanned marine vehicles with thruster faults via sliding mode technique. IEEE Trans. Cybern. $2021,1-14$. [CrossRef]

10. Yang, C.; Yao, F.; Zhang, M.J.; Zhang, Z.Q.; Wu, Z.Z.; Dan, P.J. Adaptive sliding mode PID control for underwater manipulator based on legendre polynomial function approximation and its experimental evaluation. Appl. Sci. 2020, 10, 1728. [CrossRef]

11. Jiang, Y.; Peng, Z.H.; Wang, D.; Yin, Y.; Han, Q.L. Cooperative target enclosing of ring-networked under-actuated autonomous surface vehicles based on data-driven fuzzy predictors and extended state observers. IEEE Trans. Fuzzy Syst. 2021 . [CrossRef]

12. Zhu, L.Y.; Li, T.S. Adaptive fuzzy output feedback control for intelligent ship autopilot system. J. Nanjing Univ. Inf. Sci. Technol. (Natural Sci. Ed.) $2021,13,22-28$. [CrossRef]

13. Dai, S.L.; Wang, M.; Wang, C. Neural learning control of marine surface vessels with guaranteed transient tracking performance. IEEE Trans. Ind. Electron. 2016, 63, 1717-1727. [CrossRef]

14. Dai, S.L.; He, S.D.; Wang, M.; Yuan, C.Z. Adaptive neural control of underactuated surface vessels with prescribed performance guarantees. IEEE Trans. Neural Netw. Learn. Syst. 2019, 30, 3686-3698. [CrossRef] [PubMed]

15. Li, T.S.; Zhao, R.; Chen, C.L.P.; Fang, L.Y.; Liu, C. Finite-time formation control of under-actuated ships using nonlinear sliding mode control. IEEE Trans. Cybern. 2018, 48, 3243-3253. [CrossRef]

16. Liu, L.; Wang, D.; Peng, Z.H.; Chen, C.L.P.; Li, T.S. Bounded neural network control for target tracking of underactuated autonomous surface vehicles in the presence of uncertain target dynamics. IEEE Trans. Neural Netw. Learn. Syst. 2019, 30, 1241-1249. [CrossRef]

17. Ma, H.; Liang, H.J.; Zhou, Q.; Ahn, C.K. Adaptive dynamic surface control design for uncertain nonlinear strict-feedback systems with unknown control direction and disturbances. IEEE Trans. Syst. Man Cybern. Syst. 2019, 49, 506-515. [CrossRef]

18. Peng, Z.H.; Wang, D.; Chen, Z.Y.; Hu, X.J.; Lan, W.Y. Adaptive dynamic surface control for formations of autonomous surface vehicles with uncertain dynamics. IEEE Trans. Control Syst. Technol. 2013, 21, 513-520. [CrossRef]

19. Tang, Y.G.; Wu, Y.X.; Wu, M.P.; Hu, X.P.; Shen, L.C. Nonlinear tracking differentiator for velocity determination using carrier phase measurements. IEEE J. Sel. Top. Signal Process. 2009, 3, 716-725. [CrossRef]

20. Bu, X.W.; Wu, X.Y.; Zhu, F.J.; Huang, J.Q.; Ma, Z.; Zhang, R. Novel prescribed performance neural control of a fexible air-breathing hypersonic vehicle with unknown initial errors. ISA Trans. 2015, 59, 149-159. [CrossRef]

21. Deng, H.; Krstić, M.; Williams, R.J. Stabilization of stochastic nonlinear systems driven by noise of unknown covariance. IEEE Trans. Autom. Control 2001, 46, 1237-1253. [CrossRef]

22. Liu, Y.L.; Ma, H.J. Adaptive fuzzy tracking control of nonlinear switched stochastic systems with prescribed performance and unknown control directions. IEEE Trans. Syst. Man Cybern. Syst. 2020, 50, 590-599. [CrossRef]

23. Qi, W.H.; Zong, G.D.; Zheng, W.X. Adaptive event-triggered SMC for stochastic switching systems with semi-Markov process and application to boost converter circuit model. IEEE Trans. Circuits I Regul. Papers 2021, 68, 786-796. [CrossRef]

24. Kang, S.J.; Liu, X.P.P.; Wang, H.Q. Finite-time adaptive fuzzy command filtering control for stochastic nonlinear systems with input quantization. Int. J. Adapt. Control Signal Process. 2021 , 36, 155-175. [CrossRef]

25. Do, K.D. Global robust adaptive path-tracking control of underactuated ships under stochastic disturbances. Ocean Eng. 2016, 111, 267-278. [CrossRef]

26. Jiang, Y.; He, B.; Guo, J.; Lv, P.F.; Mu, X.K.; Zhang, X.; Yu, F. Actuator weak fault diagnosis in autonomous underwater vehicle based on tri-stable stochastic resonance. Appl. Sci. 2020, 10, 2048. [CrossRef]

27. Deng, Y.J.; Zhao, D.X.; Liu, T. Self-triggered tracking control of underactuated surface vessels with stochastic noise. In Proceedings of the Name of the 2021 International Conference on Security, Pattern Analysis, and Cybernetics (SPAC), Chengdu, China, 18-20 June 2021; pp. 266-273.

28. Niu, B.; Liu, M.; Li, A. Global adaptive stabilization of stochastic high-order switched nonlinear non-lower triangular systems. Syst. Control Lett. 2020, 136, 104596. [CrossRef] 
29. Niu, B.; Zhao, P.; Liu, J.D.; Ma, H.J.; Liu, Y.J. Global adaptive control of switched uncertain nonlinear systems: An improved MDADT method. Automatica 2020, 115, 108872. [CrossRef]

30. Zhao, X.D.; Wang, X.Y.; Ma, L.; Zong, G.D. Fuzzy approximation based asymptotic tracking control for a class of uncertain switched nonlinear systems. IEEE Trans. Fuzzy Syst. 2020, 28, 632-644. [CrossRef]

31. Liu, Y.L.; Xu, S.J.; Ma, H.J. Switched-observer-based adaptive DSC design of nonstrict-feedback switched stochastic nonlinear time-delay systems. Nonlinear Anal. Hybrid Syst. 2020, 38, 100917. [CrossRef]

32. Long, L.J.; Zhao, J. Decentralized adaptive neural output feedback DSC for switched large-scale nonlinear systems. IEEE Trans. Cybern. 2017, 47, 908-919. [CrossRef] [PubMed]

33. Jia, L.; Wang, Y.N.; Zhang, C.F.; Zhao, K.H.; Liu, L.; Nguyen, X.Q. A robust adaptive trajectory tracking algorithm using SMC and machine learning for FFSGRs with actuator dead-zones. Appl. Sci. 2019, 9, 3837. [CrossRef]

34. Yang, T.; Sun, N.; Chen, H.; Fang, Y.C. Neural network-based adaptive antiswing control of an underactuated ship-mounted crane with roll motions and input dead-zones. IEEE Trans. Neural Netw. Learn. Syst. 2020, 31, 901-914. [CrossRef] [PubMed]

35. Zhao, X.D.; Shi, P.; Zheng, X.L.; Zhang, L.X. Adaptive tracking control for switched stochastic nonlinear systems with unknown actuator dead-zone. Automatica 2015, 60, 193-200. [CrossRef]

36. Tong, S.C.; Sui, S.; Li, Y.M. Observed-Based adaptive fuzzy tracking control for switched nonlinear systems with dead-zone. IEEE Trans. Cybern. 2015, 45, 2816-2826. [CrossRef] 